\title{
Carbon Dioxide Retention after Non-Cardiac Surgery in a Patient with Cor Pulmonale
}

\author{
Tak Kyu Oh, M.D.*, Hyeyeon Cho, M.D. ${ }^{\dagger}$, Dae-Soon Cho, M.D., Ph.D. ${ }^{\dagger}$ \\ *Department of Anesthesiology and Pain Medicine, Seoul National University Bundang Hospital, Seongnam, \\ ${ }^{\dagger}$ Department of Anesthesiology and Pain Medicine, National Cancer Center, Goyang, Korea
}

\author{
Correspondence to: \\ Dae-Soon Cho, M.D., Ph.D. \\ Department of Anesthesiology \\ and Pain Medicine, National \\ Cancer Center, 323 Ilsan-ro, \\ Ilsandong-gu, Goyang 10408, \\ Korea \\ Tel: +82-31-920-1462 \\ Fax: +82-31-920-1463 \\ E-mail: dschoncc@gmail.com \\ ORCID: \\ http://orcid.org/0000-0002-6326-7090
}

\begin{abstract}
Regional anesthesia is generally recommended over general anesthesia for non-cardiac surgeries in patients with severe pulmonary hypertension $(\mathrm{PH})$ caused by pulmonary disease. However, pre-, and intra-, postoperative management are critical for patients with severe $\mathrm{PH}$ even when regional anesthesia is performed. This is the first reported case of carbon dioxide retention and administration of the appropriate treatment during non-cardiac surgery performed under spinal/epidural anesthesia and analgesia in a patient diagnosed with chronic cor pulmonale accompanied by severe PH. (J Acute Care Surg 2018;8:25-29)
\end{abstract}

Key Words: Anesthesia, Critical care, Opioids

Received February 2, 2017, Revised August 9, 2017, Accepted August 10, 2017

Copyright $\odot 2018$ by Korean Society of Acute Care Surgery

(c) This is an Open Access article distributed under the terms of the Creative Commons Attribution Non-Commercial License (http://creativecommons.org/licenses/by-nc/4.0) which permits unrestricted non-commercial use, distribution, and reproduction in any medium, provided the original work is properly cited.

ISSN 2288-5862(Print), ISSN 2288-9582(Online)

https://doi.org/10.17479/jacs.2018.8.1.25

\section{Introduction}

Chronic cor pulmonale is a condition characterized by right ventricular hypertrophy secondary to pulmonary disease, which accompanies severe pulmonary hypertension (PH) [1]. The method of anesthesia must be carefully considered for patients with chronic cor pulmonale and severe $\mathrm{PH}$, as these patients have an increased risk of postoperative mortality and morbidity. Previous studies have recommended neuraxial block techniques, such as epidural anesthesia, for these patients [2]. Furthermore, analgesia provided by the epidural route is commonly recommended for patients with severe PH in order to inhibit surgical pain-induced stress and sympathetic tone [3]. Although the use of epidural opioid analgesia in combination with local anesthetics via the epidural route presents multiple advantages, opioid administration may induce potentially fatal respiratory depression. In particular, the toxicity and side effects of epidural opioids may cause more serious problems in older patients or patients with chronic pulmonary disease [4].

Here, we report the case involving a patient with a tuberculosis-destroyed lung who was diagnosed with chronic cor pulmonale accompanied by severe PH. Specifically, we report that hypercarbia developed during postoperative pain control at the surgical intensive care unit (ICU) following administration of the spinal-epidural anesthesia during non-cardiac surgery. 


\section{Case Report}

A 43-year-old woman (height, $160 \mathrm{~cm}$; weight, $42.5 \mathrm{~kg}$ ) presented with a $12.5-\mathrm{cm}$ mass in the left upper medial thigh and lower limb edema. She was diagnosed with synovial sarcoma and wide excision of the tumor was planned. She had respiratory restrictions due to a tuberculosis-destroyed lung and bronchiectasis that developed after she had contracted tuberculosis 20 years ago. She was receiving home oxygen therapy $(1.5 \sim 3 \mathrm{~L} / \mathrm{min})$ via a nasal cannula and has been maintaining $80 \%$ oxygen saturation.

Chest computed tomography (CT) showed the tuberculosisdestroyed right lung and associated tuberculosis sequelae in the left lung. CT angiography showed enlargement of the right heart and pulmonary artery, meeting the criteria for cor pulmonale. Cardiac echographic findings suggested severe tricuspid regurgitation, severe $\mathrm{PH}$ (right ventricular systolic pressure $=90.3 \mathrm{mmHg}$ ) (Fig. 1), a dilated right ventricle (RV) and right atrium, normal left ventricular contractility with an ejection fraction of $63 \%$, RV hypokinesia, and moderate pericardial effusion. Brain-type natriuretic peptide was $2,342 \mathrm{pg} / \mathrm{ml}$, and pulmonary function tests were not performed.

Preoperative vital signs at the ICU were as follows: blood pressure (BP), 95 106/66 76 $\mathrm{mmHg}$; heart rate (HR), 89 107 beats/min; and respiratory rate (RR), 18 20/min. Oxygen saturation fluctuated heavily from $55 \sim 88 \%$ depending on the

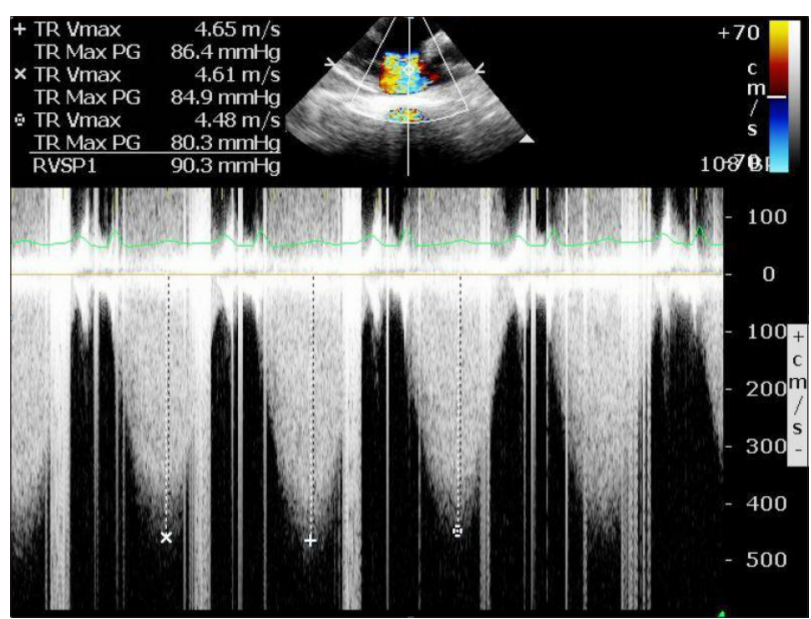

Fig. 1. Preoperative transthoracic two-dimensional echocardiography. patient's respiration and movement while receiving $3 \mathrm{~L} / \mathrm{min}$ of oxygen via the nasal cannula. Arterial blood gas analysis (ABGA) findings on the morning of the operation were as follows: $\mathrm{pH}$, 7.39; partial pressure of carbon dioxide $\left(\mathrm{PaCO}_{2}\right), 51.6 \mathrm{mmHg}$; partial pressure of oxygen $\left(\mathrm{PaO}_{2}\right), 72.2 \mathrm{mmHg}$; bicarbonate $\left(\mathrm{HCO}_{3}{ }^{-}\right), 28.5 \mathrm{mmol} / \mathrm{L}$. The patient did not complain of dyspnea and was fully conscious.

The patient was transferred to the operating room while receiving $3 \mathrm{~L} / \mathrm{min}$ oxygen via a nasal cannula without premedication. As Electrocardiogram, pulse oxygen saturation, and noninvasive BP monitoring commenced, a 20-gauge needle was inserted into the right radial artery, and a 7-Fr double-lumen catheter was inserted into the right internal jugular vein. Combined spine-epidural anesthesia was performed with the patient in the left recumbent position at the third to fourth lumbar space using a midline approach. After administering $12.5 \mathrm{mg}$ of heavy bupivacaine intrathecally, an epidural catheter was inserted. The patient was changed to the supine position to check the height of spinal anesthesia; sensory blockade reached the tenth thoracic segment after five minutes and the eighth thoracic segment after ten minutes, after which the patient was prepared for surgery. $100 \%$ Oxygen was supplied with a reservoir mask at $4 \mathrm{~L} / \mathrm{min}$. Respiratory patterns and expiratory $\mathrm{CO}_{2}$ concentration were monitored with an anesthetic machine and the concentration was well maintained without breathing difficulty. BP dropped to 78/42 $\mathrm{mmHg} 25$ minutes after intrathecal injection of bupivacaine, and subsequently $30 \mu \mathrm{g}$ of phenylephrine was intravenously infused. At 35 minutes, $30 \mu \mathrm{g}$ of intravenous (IV) phenylephrine was additionally used, during which $2 \mathrm{mg}$ of IV milrinone was infused over 10 minutes, after which it was continuously infused at 0.375 $\mu \mathrm{g} \cdot \mathrm{kg}^{-1} \cdot \mathrm{min}^{-1}$. Intraoperative ABGA showed $\mathrm{pH} 7.34, \mathrm{PaCO}_{2} 59.4$ $\mathrm{mmHg}, \mathrm{PaO}_{2} 217 \mathrm{mmHg}$, and $\mathrm{HCO}_{3}{ }^{-} 28.8 \mathrm{mmol} / \mathrm{L}$. In response to a potential drop of $\mathrm{BP}$ following the administration of milrinone, an optimal dose of norepinephrine was intravenously infused at $0.02 \sim 0.07 \mu \mathrm{g} \cdot \mathrm{kg}^{-1} \cdot \mathrm{min}^{-1}$. BP was subsequently maintained at $85 \sim 100 / 45 \sim 60 \mathrm{mmHg}$. The operation commenced approximately 40 minutes after the intrathecal injection of bupivacaine. At 80 minutes following the intrathecal injection, $5 \mathrm{ml}$ of $2 \%$ lidocaine was injected via the epidural catheter to confirm the intrathecal position of the catheter, and $10 \mathrm{ml}$ was 
additionally infused at 90 minutes. At 100 minutes, epidural patient-controlled analgesia (PCA) $(0.1875 \%$ ropivacaine, fentanyl $1.25 \mu \mathrm{g} / \mathrm{ml}$ ) was connected to begin continuous infusion at 2 $\mathrm{ml} / \mathrm{h}$ with a bolus dose of $2 \mathrm{ml}$ and a lockout time of 15 minutes. BP remained stable and so norepinephrine was stopped, followed by cessation of milrinone administration at 130 minutes. The surgery concluded without adverse events, and the patient was transferred to the ICU. The total duration of anesthesia and operative time were 2 hours and 55 minutes and 1 hour and 40 minutes, respectively. Intraoperative fluid levels included administration of $450 \mathrm{ml}$ of crystalloid, urinary output was 115 $\mathrm{ml}$, and less than $10 \mathrm{ml}$ of estimated blood was lost.

ABGA at the ICU showed pH 7.3, $\mathrm{PaCO}_{2} 66.4 \mathrm{mmHg}, \mathrm{PaO}_{2}$ $50.1 \mathrm{mmHg}$, and $\mathrm{HCO}_{3}^{-} 27.9 \mathrm{mmol} / \mathrm{L}$. The patient was conscious with no dyspnea, and her vital signs were BP 92/53 $\mathrm{mmHg}$, HR 123 beats/min, RR 16 beats/min, and pulse oxygen saturation $67 \%$. Oxygen was supplied with a nasal cannula at $3 \mathrm{~L} / \mathrm{min}$. The level of anesthesia was at T12, and pain score (numeric rating scale, NRS) was 0.

There were no marked differences between preoperative and postoperative chest radiographs (Fig. 2). On postoperative day (POD) 0 in the ICU, pain (NRS, $0 \sim 3)$ and RR (18 24 beats/min) were well controlled under epidural PCA as the level of anesthesia decreased. On POD 1, oxygen continued to be given via a nasal cannula at $3 \mathrm{~L} / \mathrm{min}$, and the patient's NRS was $0 \sim 2$ and $\mathrm{RR}$ was $18 \sim 25$ beats/min. ABGA showed $\mathrm{pH}$ 7.29, $\mathrm{PaCO}_{2} 69.8 \mathrm{mmHg}, \mathrm{PaO}_{2} 53.9 \mathrm{mmHg}$, and $\mathrm{HCO}_{3}{ }^{-} 28.1$ mmol/L. Cardiac echography performed on POD 1 did not show changes to the RV hypokinesia and severe PH compared to the preoperative conditions. On POD 2, the patient showed mental drowsiness, and ABGA revealed $\mathrm{pH} 7.27, \mathrm{PaCO}_{2} 75.1 \mathrm{mmHg}$, $\mathrm{PaO}_{2} 31.6 \mathrm{mmHg}$, and $\mathrm{HCO}_{3}^{-} 27.6 \mathrm{mmol} / \mathrm{L}$, with a reduction in $\mathrm{RR}$ to $12 \sim 15$ beats/min.

Epidural PCA was immediately turned off, and Biphasic Intermittent Positive Airway Pressure (BIPAP) ventilation was administered and endotracheal intubation prepared (positive end-expiratory pressure $5 \mathrm{cmH}_{2} \mathrm{O}$, pressure support $7 \mathrm{cmH}_{2} \mathrm{O}$, fraction of inspired oxygen 0.3). Target $\mathrm{PaO}_{2}$ and $\mathrm{PaCO}_{2}$ were $40 \mathrm{mmHg}$ and $60 \mathrm{mmHg}$, respectively. ABGA on POD 3 showed $\mathrm{pH}$ 7.3, $\mathrm{PaCO}_{2} 73.8 \mathrm{mmHg}, \mathrm{PaO}_{2} 68.8 \mathrm{mmHg}$, and $\mathrm{HCO}_{3}{ }^{-} 30.9$ $\mathrm{mmol} / \mathrm{L}$, while that on POD 4 showed $\mathrm{pH} 7.38, \mathrm{PaCO}_{2} 68.8$ $\mathrm{mmHg}, \mathrm{PaO}_{2} 52.5 \mathrm{mmHg}$, and $\mathrm{HCO}_{3}{ }^{-} 36.9 \mathrm{mmol} / \mathrm{L}$, suggesting an improvement. On POD 4, the patient complained of pain (NRS 6 once), and morphine $3 \mathrm{mg}$ was intravenously administered. As the patient's RR decreased and the patient showed mental drowsiness again, her pain levels were controlled using nonsteroidal anti-inflammatory drugs. The patient improved from POD 5, POD 6, and POD 7 respectively, with improvements

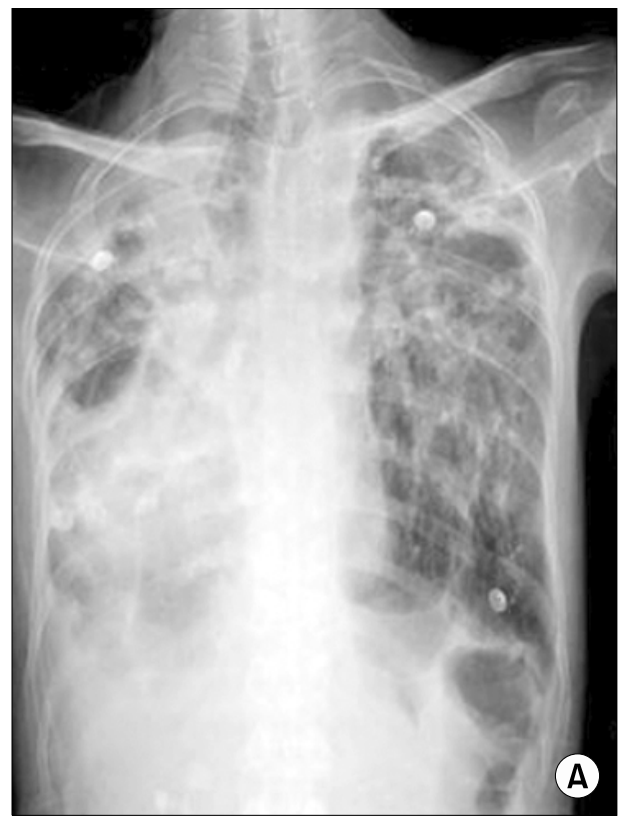

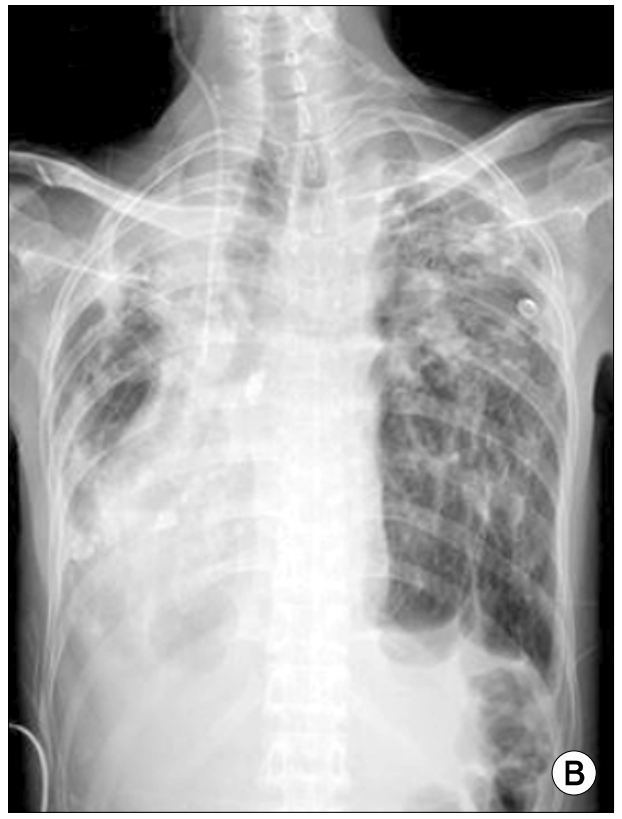

Fig. 2. Preoperative (A) and postoperative (B) chest radiographs. 
noted in $\mathrm{pH}$ (7.38-7.43-7.47), $\mathrm{PaCO}_{2}(68.8-59.2-56.9 \mathrm{mmHg})$, and $\mathrm{PaO}_{2}$ (68.8-59.2-56.9 mmHg), and was transferred to a nearby hospital.

\section{Discussion}

Anesthetic management for patients with severe $\mathrm{PH}$ has been extensively studied and reported [3,5]. We performed regional anesthesia on a patient with severe $\mathrm{PH}$, using the recommendations provided by previous studies [2]. Further, we performed epidural analgesia for pain control to prevent the exacerbation of RV failure caused by surgical stress and postoperative pain [3]. However, the patient's $\mathrm{CO}_{2}$ retention continued to deteriorate compared to preoperative conditions, which was safely recovered through BIPAP ventilation. In other words, this case is worthy of reporting, as $\mathrm{CO}_{2}$ retention was exacerbated in a patient with chronic cor pulmonale with severe $\mathrm{PH}$ even after an adequate level of regional anesthesia was achieved.

Compared to the preoperative $\mathrm{PaCO}_{2}(51.6 \mathrm{mmHg}$ ), the patient's $\mathrm{CO}_{2}$ levels continued to rise, with $\mathrm{PaCO}_{2}$ reaching 59.4 $\mathrm{mmHg}$ intraoperatively and $66.4 \mathrm{mmHg}$ immediately following surgery. Although we continuously confirmed that the spinal block did not rise above the T8 level intraoperatively, there is a possibility that the anesthetic level impaired the ventilatory function by inducing respiratory muscle weakness. It is well known that respiratory function during spinal anesthesia may induce respiratory depression by affecting rib cage movement and abdominal wall movement [6]. This would not pose a serious problem for healthy patients, but spinal anesthesia has the potential to critically effect the ventilatory function in patients with chronic cor pulmonale such as the patient in this case.

Another factor to consider is the possibility of excessive oxygen therapy during surgery. The patient was receiving chronic home oxygen therapy at $1.5 \mathrm{~L} \sim 3 \mathrm{~L} / \mathrm{min}$ via a nasal cannula. The patient's $\mathrm{PaO}_{2}$ on the morning of the operation was $72.2 \mathrm{mmHg}$. It has been reported that excessive oxygen therapy for patients with chronic pulmonary disease exacerbates $\mathrm{CO}_{2}$ retention by decreasing ventilatory responses [7]. An intraoperative switch to a facial mask with a $4 \mathrm{~L} / \mathrm{min}$ reservoir from $3 \mathrm{~L} / \mathrm{min}$ of oxygen via a nasal cannula for safety during anesthesia might have actually induced $\mathrm{CO}_{2}$ retention during surgery. In fact, the patient's intraoperative $\mathrm{PaO}_{2}$ was $217 \mathrm{mmHg}$, which is about a three-fold increase from her preoperative $\mathrm{PaO}_{2}$, and considering the patient's history of cor pulmonale, this might have been the cause of $\mathrm{CO}_{2}$ retention.

Finally, the most important issue related to the patient's $\mathrm{CO}_{2}$ retention is epidural opioid analgesia. This is because the patient was an opioid naive patient; continuous infusion of epidural PCA was commenced intraoperatively, and $\mathrm{PaCO}_{2}$ gradually increased until POD 2 where $\mathrm{PaCO}_{2}$ reached $75.1 \mathrm{mmHg}$, while the RR decreased. Further, considering the event in which the patient's $\mathrm{CO}_{2}$ retention suddenly peaked with $\mathrm{IV}$ infusion of $3 \mathrm{mg}$ morphine while she was gradually improving and her $\mathrm{CO}_{2}$ levels reduced after the epidural PCA was turned off and BIPAP ventilation was applied, we could speculate that the epidural fentanyl might have been the most likely cause of $\mathrm{CO}_{2}$ retention in our patient with chronic cor pulmonale. Epidural fentanyl has been known to decrease ventilatory response [8], and the optimal dose remains controversial. The guideline protocol from a previous study recommends the use of epidural fentanyl at a base rate of $0.008 \sim 0.17 \mu \mathrm{g} \cdot \mathrm{kg}^{-1} \cdot \mathrm{min}^{-1}$ [9]. However, in our case, epidural fentanyl was continuously infused at $2.5 \mu \mathrm{g} / \mathrm{h}$, which was only a small fraction of the recommended dose. Despite the low dose, epidural fentanyl may still have caused the $\mathrm{CO}_{2}$ retention due to the patient's chronic pulmonary disease with cor pulmonale as well as her sensitivity to opioids.

Finally, the appropriateness of the management at ICU, i.e., performing BIPAP ventilation and not using naloxone, should be reviewed. Based on the reports of a previous study where early use of non-invasive ventilation was effective in chronic obstructive pulmonary disease [10], our decision to apply BIPAP ventilation early in this patient presenting with cor pulmonale which is a chronic pulmonary disease, was appropriate. At the same time, we chose not to use naloxone because the patient's condition was not life-threatening, and activation of the sympathetic nervous system might have exacerbated the patient's right heart failure. As a result, although $\mathrm{CO}_{2}$ retention progressed, we were able to facilitate recovery to the preoperative status by applying BIPAP ventilation before the symptoms progressed to a critical condition. 
In conclusion, as previous studies have recommended, regional anesthesia is recommended for non-cardiac surgery in patients with chronic cor pulmonale accompanied by severe $\mathrm{PH}$. However, as demonstrated in our case, even a mild increase in the anesthetic level may cause complications, and an excessive oxygen level may also be inappropriate. In addition, a low epidural opioid dose may decrease the patient's ventilatory response. This case is meaningful as it is the first report that provides insight into the factors that must be considered during non-cardiac surgery of patients with chronic cor pulmonale accompanied by severe $\mathrm{PH}$. In these patients, we recommend anesthesiologists perform regional anesthesia with an appropriate anesthetic level, avoid excessive oxygen, and adequately use epidural analgesia using local anesthetics alone without opioids.

\section{Conflicts of Interest}

No potential conflict of interest relevant to this article was reported.

\section{References}

1. Weitzenblum E. Chronic cor pulmonale. Heart 2003;89:225-30.

2. Ramakrishna G, Sprung J, Ravi BS, Chandrasekaran K,
McGoon MD. Impact of pulmonary hypertension on the outcomes of noncardiac surgery: predictors of perioperative morbidity and mortality. J Am Coll Cardiol 2005;45:1691-9.

3. Lai HC, Lai HC, Wang KY, Lee WL, Ting CT, Liu TJ. Severe pulmonary hypertension complicates postoperative outcome of non-cardiac surgery. Br J Anaesth 2007;99: 184-90.

4. Gruber EM, Tschernko EM. Anaesthesia and postoperative analgesia in older patients with chronic obstructive pulmonary disease: special considerations. Drugs Aging 2003;20: 347-60.

5. Nawaaz MS, Salem Y. Right hemicolectomy in a patient with severe pulmonary hypertension anesthesia approach. Anesth Essays Res 2010;4:38-40.

6. Yamakage M, Kamada Y, Toriyabe M, Honma Y, Namiki A. Changes in respiratory pattern and arterial blood gases during sedation with propofol or midazolam in spinal anesthesia. J Clin Anesth 1999;11:375-9.

7. Moloney ED, Kiely JL, McNicholas WT. Controlled oxygen therapy and carbon dioxide retention during exacerbations of chronic obstructive pulmonary disease. Lancet 2001;357:526-8.

8. Negre I, Gueneron JP, Ecoffey C, Penon C, Gross JB, Levron JC, et al. Ventilatory response to carbon dioxide after intramuscular and epidural fentanyl. Anesth Analg 1987; 66:707-10.

9. de Leon-Casasola OA, Lema MJ. Postoperative epidural opioid analgesia: what are the choices? Anesth Analg 1996;83:867-75.

10. Plant PK, Owen JL, Elliott MW. Early use of non-invasive ventilation for acute exacerbations of chronic obstructive pulmonary disease on general respiratory wards: a multicentre randomised controlled trial. Lancet 2000;355:1931-5. 